\title{
PERANCANGAN SISTEM INFORMASI BERBASIS APLIKASI DENGAN METODE COSTUMER RELATIONSHIP MANAGEMENT (CRM) PADA BARBERSHOP (STUDI KASUS: SIAN BARBERSHOP)
}

\author{
Marsellinus Bachtiar ${ }^{1}$, Edwin Steven Togar Marnaek ${ }^{2}$ \\ ${ }^{1,2}$ Program Studfi Teknik Industri, Universitas Katolik Indonesia, Atma Jaya-Jakarta \\ Email: marsellinus.bachtiar@atmajaya.ac.id
}

\begin{abstract}
Currently, technology is relevant to people's lives because people use technology daily for activities, work, transactions and various aspects of life. Information systems have an important role in everything, one of which is for economic growth and also helps provide information to the public easily. Sian Barbershop is engaged in shaving services and requires a good information system, because the most important business processes for Sian Barbershop are Online Booking and administration. The current problem is that Sian Barbershop still uses conventional methods and still uses written records. On the other hand, long queues are one of the factors that make online ordering systems important for customer convenience. The purpose of this writing and design is a new method where online booking will help customers shave their hair at Sian Barbershop and support existing business processes. The information system that will be designed using Adobe Xd is aimed at selling and attracting the attention of MSME customers. In the design methodology, the steps that need to be done in making this information system are mapping information needs, design and construction of information systems. The result of the design is that the information system application that has been designed and designed has fulfilled the booking function (in $C R M)$ in accordance with the indicators that have been made. The design of this information system already has a usability factor where the information system is feasible and can also be implemented for these SMEs.
\end{abstract}

Keywords: Adobe XD, Information System, Online Payment

\begin{abstract}
ABSTRAK
Saat ini teknologi menjadi hal yang relevan dengan kehidupan masyarakat karena keseharian masyarakat menggunakan teknologi untuk beraktifitas, bekerja , bertransaksi dan berbagai aspek hidup. Sistem informasi mempunyai peran penting dalam segala hal salah satunya untuk pertumbuhan ekonomi dan juga membantu memberikan informasi kepada masyarakat dengan mudah. Sian Barbershop bergerak di bidang jasa mencukur dan membutuhkan sistem informasi yang baik, karena proses bisnis yang paling penting untuk Sian Barbershop adalah Booking Online dan administrasi. Permasalahan saat ini, Sian Barbershop masih menggunakan metode konvensional dan masih menggunakan catatan tertulis. Di sisi lain antrian yang cukup panjang menjadi salah satu faktor yang membuat sistem pemesanan daring menjadi penting bagi kenyamanan pelanggan. Tujuan dari penulisan dan perancangan ini adalah metode baru dimana adanya booking online ini akan membantu para pelanggan mencukur rambut di Sian Barbershop dan menunjang proses bisnis yang ada. Sistem Informasi yang akan dirancang menggunakan Adobe Xd yang tertuju penjualan dan menarik perhatian costumer UMKM. Dalam Metodologi perancangan, tahap yang perlu dilakukan dalam membuat sistem informasi ini seperti adalah pemetaan kebutuhan informasi, desain dan konstruksi sistem informasi. Hasil dari perancangan adalah aplikasi sistem informasi yang sudah dirancang dan di desain sudah memenuhi fungsi booking (dalam CRM) sesuai dengan indikator yang sudah dibuat. Perancangan sistem informasi ini sudah memiliki faktor usability dimana sistem informasi sudah layak dan juga bisa diimplementasikan ke UMKM ini.
\end{abstract}

Kata Kunci: Adobe Xd, Sistem Informasi, Pesanan daring 


\section{PENDAHULUAN}

\section{Latar Belakang}

Perkembangan teknologi memberikan terobosan pada kemudahan pekerjaan manusia dan menggantikan aktifitas-aktifitas yang berulang, manual, berbahaya dan kurang efisien. Dengan pemanfaatan teknologi, maka manusia dapat melakukan pekerjaan lain yang mempunyai kemanfaatan lebih - alih-alih mengerjakan task yang tidak efisien.

Perkembangan perdagangan dan industri (barang dan jasa) membutuhkan informasi yang cepat , akurat dan memiliki peran besar dalam operasionalisasi setiap usaha - termasuk UMKM. Pada perkembangan di era sekarang ini juga, teknologi informasi akan sangat membantu pekerjaan yang sifatnya rutin, berbahaya - sehingga jauh lebih efisien dan memberikan nilai tambah bagi bisnis . Gellinas and Dull (2012) menyatakan bahwa informasi merupakan data yang disajikan dalam suatu bentuk yang berguna terhadap aktifitas pengambilan keputusan. Informasi juga merupakan sarana pengambilan keputusan yang tentunya yang akan membantu suatu UMKM dalam menyelesaikan masalah. Artinya adanya informasi ini - membuat pengambilan keputusan menjadi lebih tajam dan obyektif karena didasari pada referensi yang valid,

Usaha potong rambut (barbershop) merupakan bisnis jasa pelayanan penataan dan pemotongan rambut maupun janggut (khususnya market laki-laki) dengan menggunakan tempat, peralatan dan sumber data lainnya yang mendukung. Para pria saat ini sangat memperhatikan penampilan, termasuk pakaian, gadget, dan juga gaya rambut. Dalam tahun-tahun terakhir peluang bisnis ini ditangkap oleh penyedia-penyedia layanan dan barbershop makin menjamur terutma di kotakota. Pada tahun 2020 tercatat 10.000 gerai atau merek barbershop di Indonesia dengan skala yang beragam. Ade Farolan - ketua Asosiasi Barbershop Indonesia pertumbuhan bisnis diproyeksikan tumbuh 30\% pada tahun 2017 dan akan terus bertambah (Aprilyani,2017). Hal ini memberikan sinyal bahwa masih ada peluang tumbuh untuk jasa ini seiring dengan meningkatnya jumlah milenial dan demografi.

Disisi lain, menjamurnya jumlah penyedia layanan barber -membuat konsekuensi persaingan semakin tinggi dan memberikan banyak pilihan bagi konsumen. Jasa barbershop merupakan pasar yang memililki diferensiasi rendah antar produk, entry barrier yang relative rendah dan skala usaha yang beragam. Dalam situasi ini dibutuhkan strategi yang tepat untuk barbershop untuk dapat survive dalam persaingan dan mengambil ceruk pasar yang makin kompetitif. Faktor-faktor pendukung baik teknis (keahlian tenaga kerja di barbershop, fasilitas, pelayanan, tempat) dan non-teknis (brand, engagement, value) memberikan pengaruh penting dalam keberadaan barbershop. Hubungan antara barbershop dengan pelanggan (customer engagement) dalam bentuk layanan terhadap pelanggan memberikan efek penting untuk repeat order (Merina, 2017). Saat ini kecenderungan konsumen adalah barbershop yang memberikan penataan ruangan dengan suatu tema khusus - sebagai bentuk diferensiasi dalam persaingan.

Sian Barber memiliki goals peningkatan penjualannya dengan menggunakan strategi yang relevan dan horizon waktu jangka panjang. Strategi ini dituangkan dalam inisiatif pembuatan CRM (Customer Relationship Management) yang merupakan sistem untuk menghubungkan pelanggan dan perusahaan dengan tujuan ada repeat order di kemudian hari.

Kapabilitas CRM dapat memberikan impact pada mempertahankan pelanggan tetap, peningkatan penjualan dengan cara cross selling antar layanan, dan akuisisi pelanggan baru. Hal ini dapat diraih dengan pemanfaatan data-data akurat dan valid di CRM. Pelanggan baru dapat memperkaya database pelanggan yang ada dan dengan memprofiling data dan kebutuhan yang tepat - akan dapat meningkatkan penjualan . CRM sebagai suatu sistem membutuhkan integrasi dari berbagai fungsi dan lini bisnis dan juga analisis atas data sehingga didapatkan insight atas kebutuhan pelanggan potensial . Tujuan dari perancangan sistem sistem CRM ini adalah agar seluruh proses atas informasi mengenai pelanggan ini dapat diintegrasikan dan dapat diakses dengan mudah oleh manajemen. 


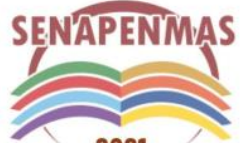

2021
Seminar Nasional Hasil Penelitian dan Pengabdian Kepada Masyarakat 2021

Pengembangan Ekonomi Bangsa Melalui Inovasi Digital Hasil Penelitian dan Pengabdian Kepada Masyarakat Jakarta, 21 Oktober 2021

\section{Rumusan Masalah}

Dalam mencapai suatu tujuan barbershop salah satunya dengan meningkatkan penjualan. Hal ini dapat dicapai dengan cara meningkatkan pelanggan baru, mempertahankan pelanggan tetap, dan meningkatkan cross-selling. Permasalahan yanhg dirumuskan adalah bagaimana merancang suatu sistem CRM terintegrasi dalam proses bisnis dan dapat memberikan kemudahan terutama bagi pelanggan dalam bertransaksi.

Berdasarkan latar belakang di atas, masalah yang diteliti dari :

1. Rancangan sistem seperti apa yang mampu membuat Sian Barber bisa mencapai tujuan?

2. Bagaimana tampilan rancangan sistem yang akan dibuat?

3. Manfaat dari sistem CRM yang dirancang .

\section{METODE PENELITIAN}

Metode penelitian dilakukan secara tahapan dengan mengidentifikasikan kebutuhan user atas informasi dan menggunakan alur perancangan perangkat lunak.

Mengidentifikasikan kebutuhan user dilakukan dengan identifikasi kebutuhan bisnis proses dan data. Pengumpulan data yang valid akan memberikan landasan. Setelah data diperoleh, maka pada proses pengolahan data ini dilakukan perancangan CRM sesuai dengan mengurai proses bisnis dan aliran informasi pada Sian Barber.

Langkah berikutnya adalah analisa sistem apakah sesuai dengan kebutuhan user dan bisnis dan kualitas . Perbandingan antara sistem baru (usulan) - dengan aplikasi (dan terkomputerisasi) dengan sistem konvensional dengan system yang baru dibandingkan dengan metriks termasuk efisiensi dan efektifitas. Untuk memastikan aplikasi ini berjalan dengan lancar, uji coba dilakukan dengan usability test.

Tahap terakhir adalah membuat kesimpulan atas keseluruhan sistem CRM yang dirancang yang dampaknya pada usaha. Langkah-langkah ini dapat dilihat pada gambar 2 , dibawah ini. 
Seminar Nasional Hasil Penelitian dan Pengabdian Kepada Masyarakat 2021

Pengembangan Ekonomi Bangsa Melalui Inovasi Digital Hasil Penelitian dan

Pengabdian Kepada Masyarakat

Jakarta, 21 Oktober 2021

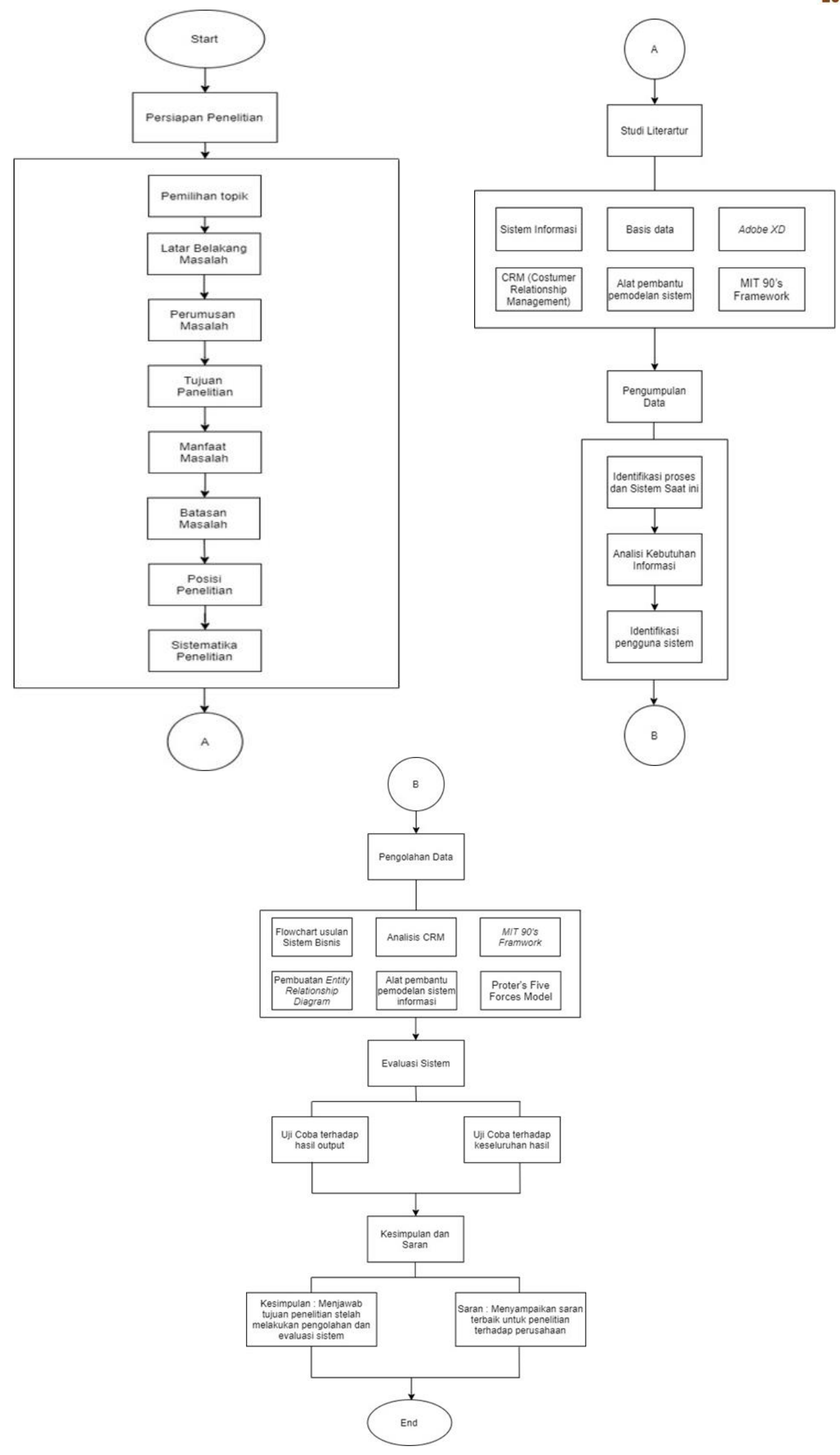

Gambar 1. Metode Penelitian 


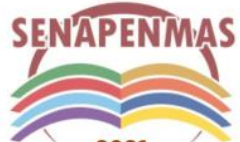

2021
Seminar Nasional Hasil Penelitian dan Pengabdian Kepada Masyarakat 2021

Pengembangan Ekonomi Bangsa Melalui Inovasi Digital Hasil Penelitian dan Pengabdian Kepada Masyarakat Jakarta, 21 Oktober 2021

\section{HASIL DAN PEMBAHASAN}

Pada gambar 1 dibawah ini memperlihatkan diagram konteks dan digambarkan aliran informasi untuk proses booking - antara admin dan pelanggan di Sian Barbershop. Diagram konteks (Context Diagram) memetakan setiap entitas, dalam hal ini adalah entitas Kasir, Barberman, pelanggan dan juga Manager. Sistem informasi booking ini mempertemukan pelanggan yang melakukan booking dan admin Sian Barber (back end) menerima order dari sistem dan pada akhirnya sistem memberikan umpan balik berupa konfirmasi atas booking.

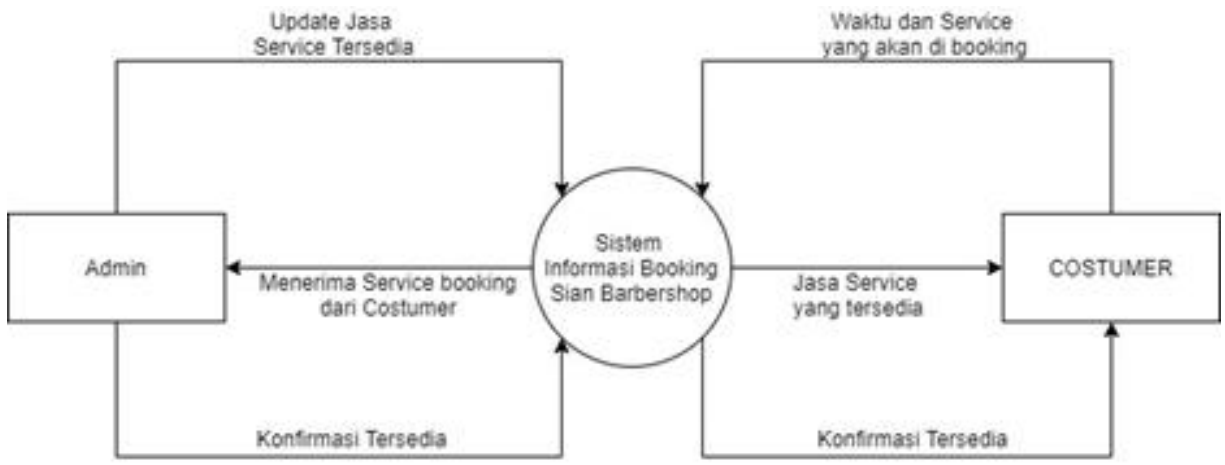

Gambar 2. Context Diagram

Sumber Gambar: Diolah dari proses internal

Langkah berikutnya adalah pembuatan Data flow Diagram (DFD) untuk menggambarkan seluruh aliran data yang sedang berjalan dalam suatu sistem sebagai turunan dari diagram konteks diatas. Dekomposisi Data Flow diagram dilakukan dengan membagi ke tingkatan (level) DFD Level 2, DFD Level 3 dan seterusnya - yang mengindikasikan semakin detil seluruh aliran proses informasi yang terdapat pada sistem usulan ini. DFD Level 1 (Gambar 3) memberikan penjelasan atas entitas Customer dan Admin dan proses 1.1. (Mengelola Informasi Pelanggan), 1.2. Mengelola Data Booking, 1.3 Melihat Status Booking dan 1.4. Perhitungan Harga

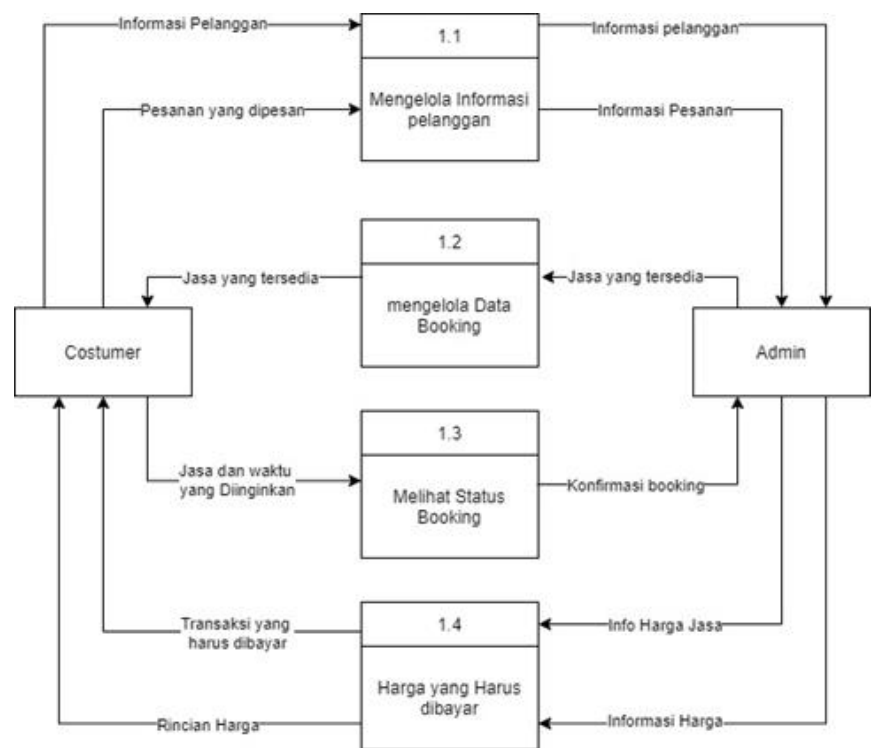

Gambar 3. DFD Level 1

Sumber Gambar: Diolah dari internal 
Setelah DFD 1, maka dirancang DFD level 2 sebagai dekomoposisi atas proses/sub-proses diatas dan aliran data yang lebih rinci dari fungsi- fungsi yang ada pada DFD level 1 - seperti :Mengelola Informasi pelanggan, mengelola data booking, melihat status booking dan juga Harga Service yang ada. Rancangan Data Flow diagram untuk level 2 yakni sebagai berikut:

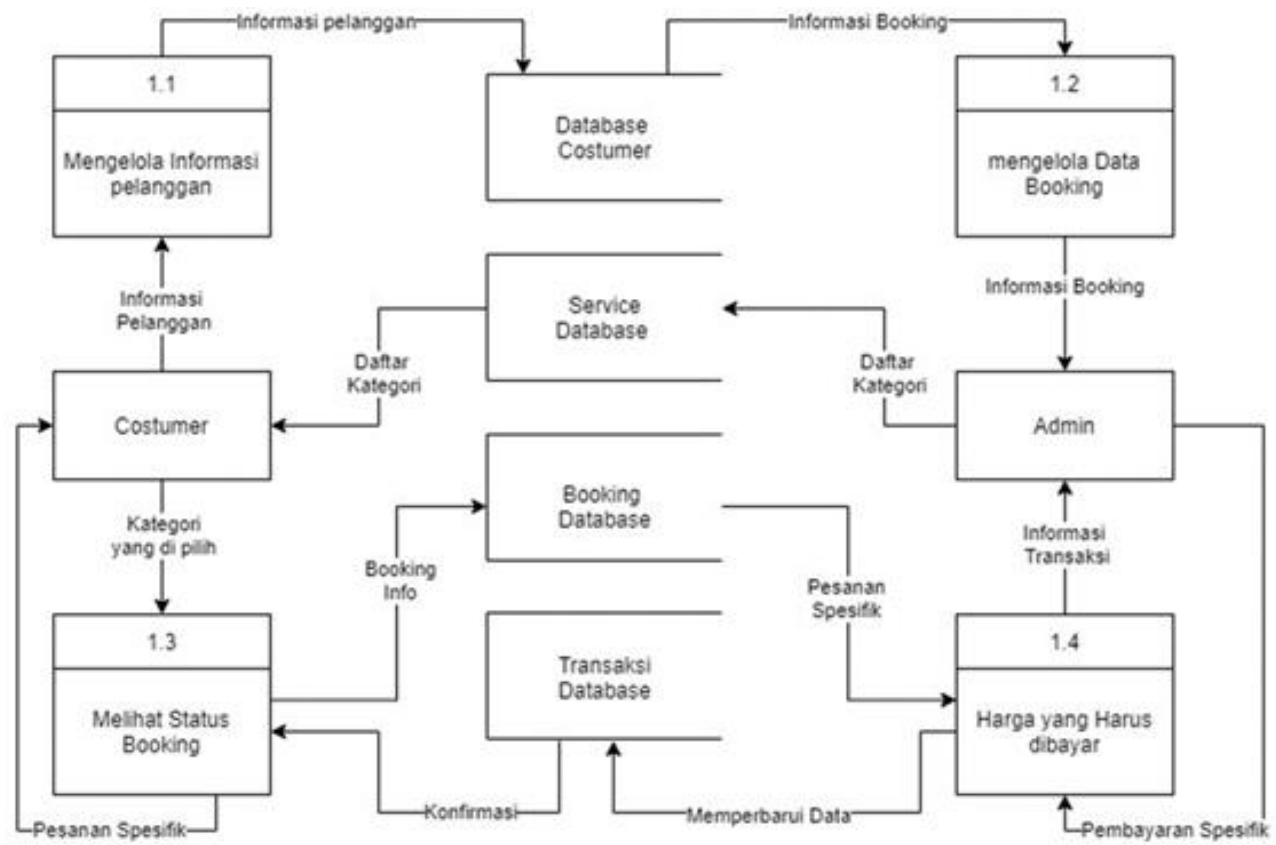

Gambar 4. DFD Level 2

Sumber Gambar: Diolah dari internal

Dalam rancangan DFD Level 2 (gambar 4) diidentifikasikan beberapa database yaitu Database Customer, Database Service, Database Booking dan Database Transaksi .

Selanjutnya dirancang Entity Relationship Diagram (ERD) untuk mengetahui hubungan antar data dalam suatu basis data (Gambar 5). Korelasi data antar table-tabel dapat dilihat disini termasuk penentuan primary key.

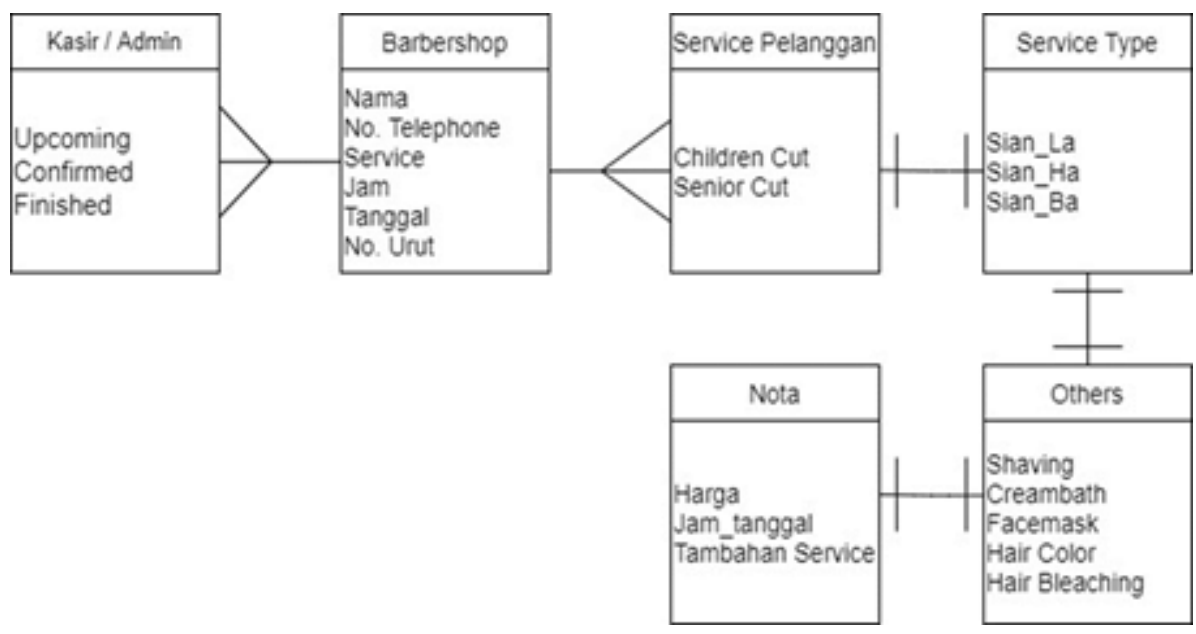

Gambar 5. ERD

Sumber Gambar: Diolah dari Internal 


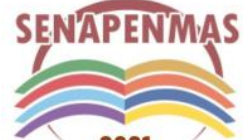

2021
Seminar Nasional Hasil Penelitian dan Pengabdian Kepada Masyarakat 2021

Pengembangan Ekonomi Bangsa Melalui Inovasi Digital Hasil Penelitian dan Pengabdian Kepada Masyarakat Jakarta, 21 Oktober 2021

Selanjutnya adalah perancangan aplikasi (android) berdasarkan referensi Context Diagram, DFD dan ERD - dimana aplikasi ini dimaksudkan sebagai platform yang mempertemukan user (pelanggan) dengan pihak Barbershop. Aliran halaman dalam perancangan aplikasi ini mengikuti alur proses user mulai dari booking sampai dengan pembayaran. Disamping itu rancangan UI/UX juga mempertimbangkan kenyamanan user (baik pelanggan maupun admin) dalam menggunakan sistem.

Pada tampilan aplikasi (Tabel 1) diperlihatkan screenshoot dari rancangan aplikasi yang dibuat mulai dari registrasi user, proses booking sampai dengan konfirmasi. Pada proses register, data-data penting pelanggan masuk dalam database untuk selanjutnya pelanggan terdaftar sebagai user aplikasi ini .

Pada tampilan booking, pelanggan memasukan informasi waktu yang diinginkan dan jenis layanan berdasarkan tabel layanan dan harga yang diberikan. Informasi-informasi ini akan diproses di sistem dan setelah semua terisi , maka pelanggan akan mendapatkan konfirmasi atas booking nya.

Tabel 1. Tampilan Aplikasi

Sumber : Perancangan

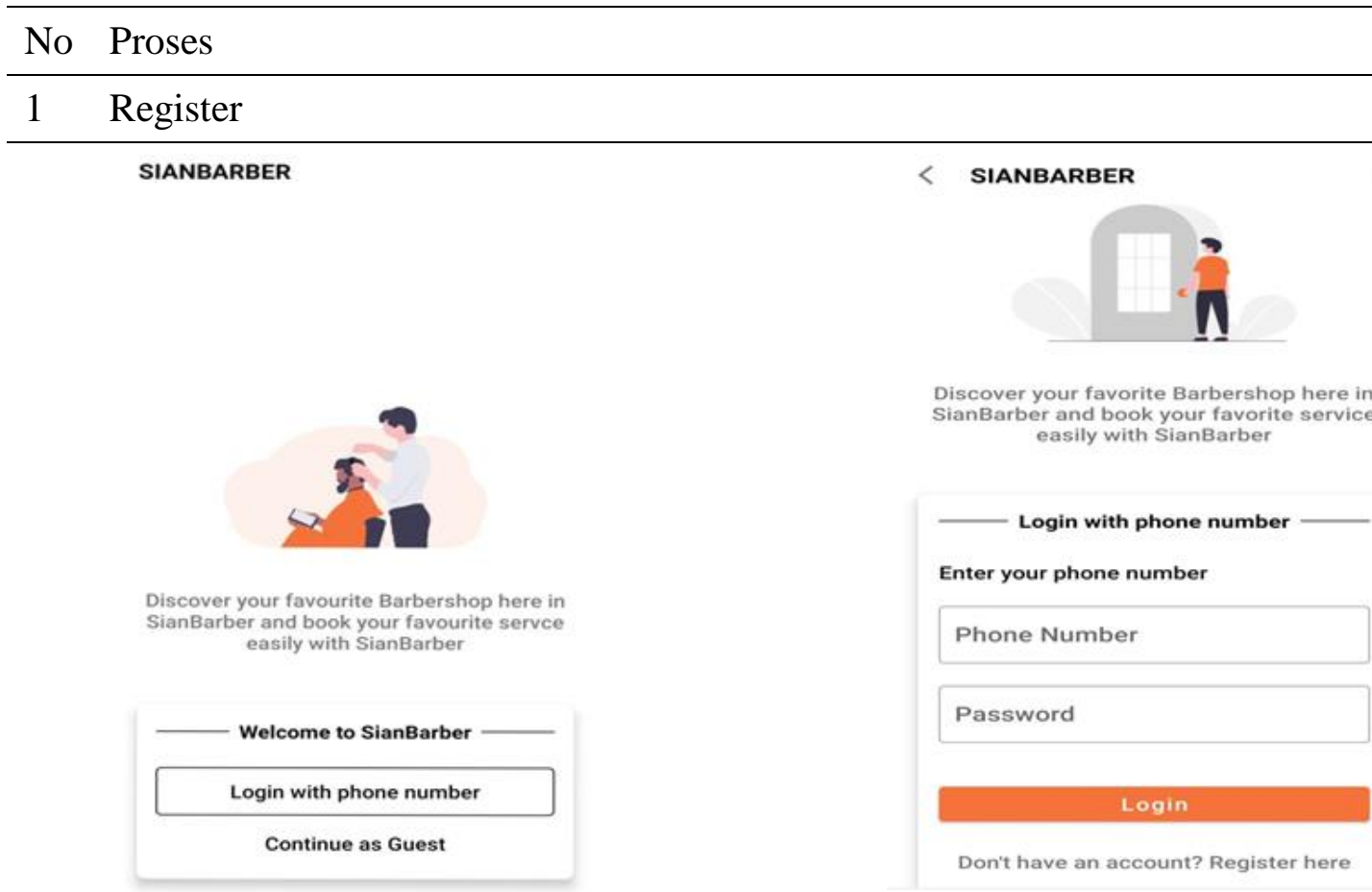




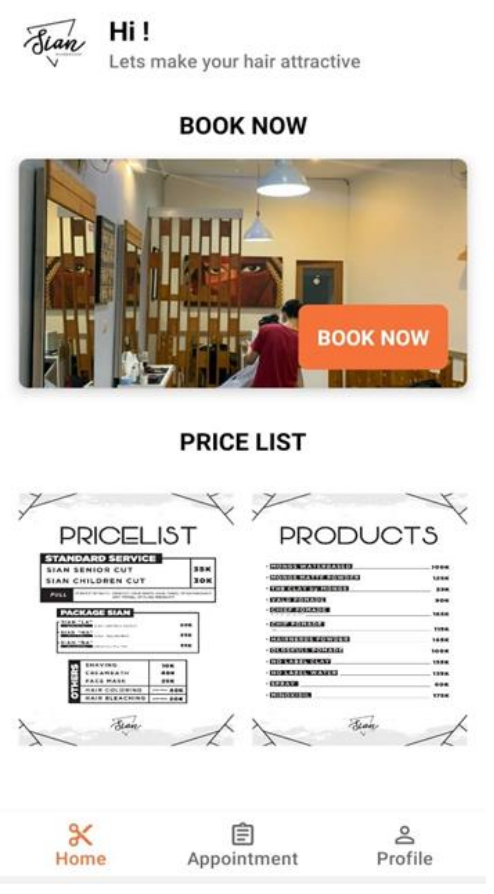

\section{$<$ SIANBARBER}

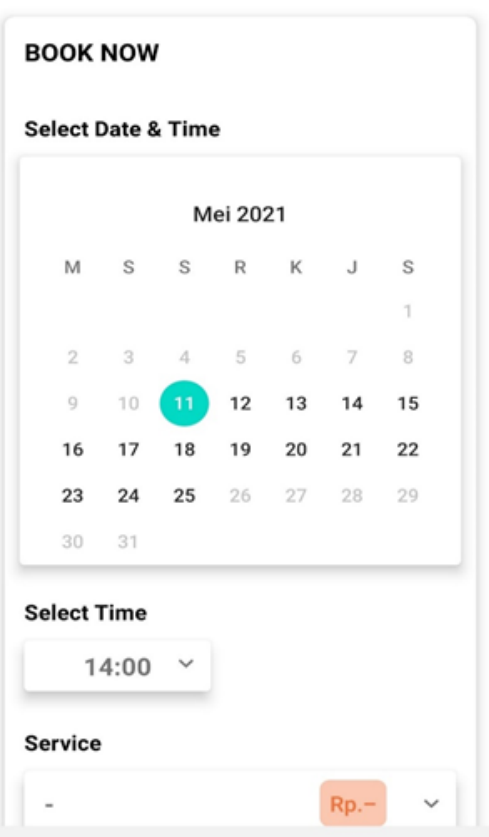

$3 \quad$ Konfirmasi

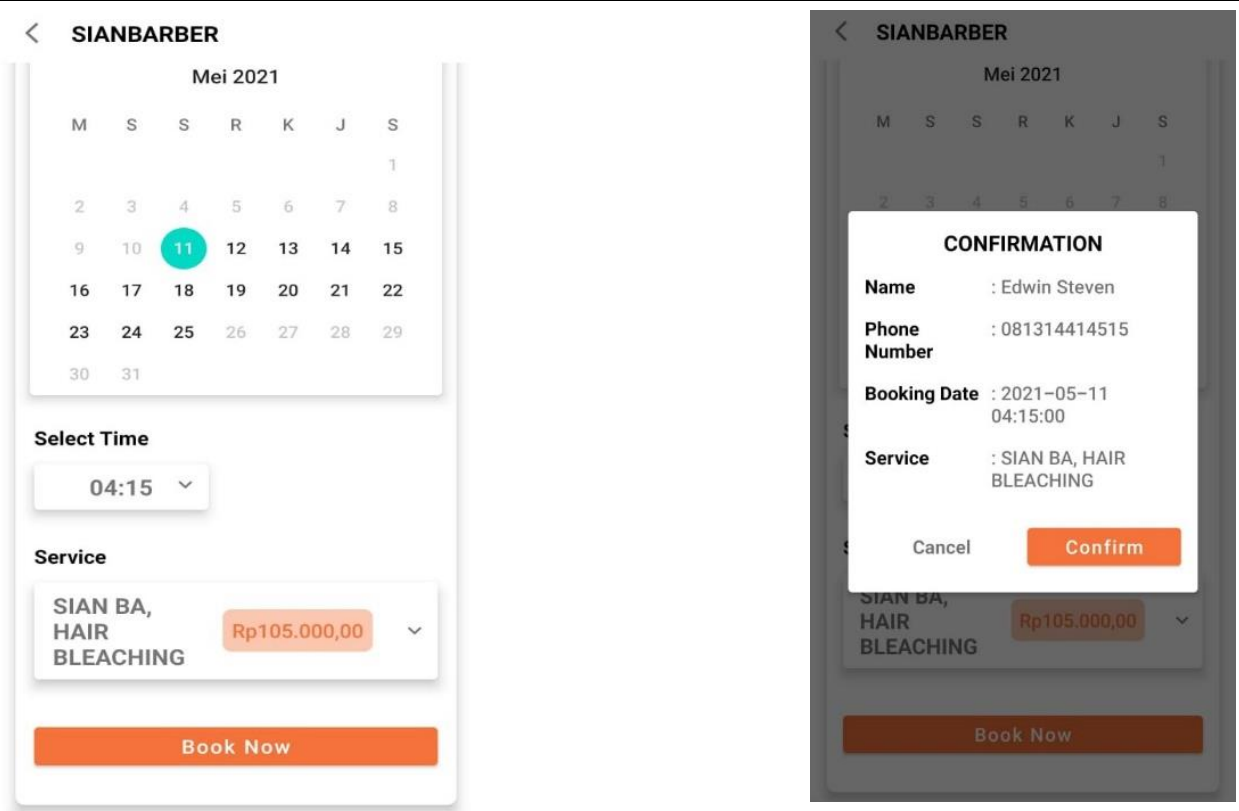

Pengujian atas aplikasi ini dilakukan dengan pengujuan atas fungsi-fungsi itu sendiri (System Test) dan pengujian dari sisi user (User Acceptance Test/UAT). UAT ini bermanfaat untuk mendapatkan masukan dan mengetahui bagian-bagian yang harus direvisi agar sesuai dengan fungsi dan hasil yang diinginkan. Pengujian dilakukan terhadap 30 (tiga puluh) responden untuk mengetahui apakah aplikasi serta fitur-fiturnya sesuai dengan rancangan atas kebutuhan pengguna. Tabel 2 dibawah ini memperlihatkan hasil pengujian UAT untuk beberapa kriteria yaitu : Tampilan, Fungsi dan Kemudahan. 
Mekanisme pengujian dilakukan sebagai berikut :

1. Aplikasi ditunjukan kepada responden.

2. Responden diminta untuk menggunakan semua jenis fitur fungsional yang ada.

3. Kepada pengguna diberikan pertanyaan terkait isi kuesioner terkait usability dan kesesuaian .

4. Pengolahan hasil feedback / nilai dan memberikan catatan kesimpulan apakah UAT diterima atau ditolak.

\section{Validasi Sistem}

Pada tahap validasi sistem, konstruksi sistem informasi pada Aplikasi Sian Barbershop diuji dengan menyandingkan konstruksi sistem informasi ini dengan requirement definition pada tahap perancangan. Esensinya adalah sistem ini memberikan output sesuai dengan yang seharusnya diharapkan - yaitu booking yang valid dari kacamata pelanggan . Penilaian akhir nya adalah fitness antara dari kebutuhan si pengguna dan fungsi sistem informasi dan kebenaran dari nilai output atas setiap input. Sebagai contoh pengertian valid adalah : bila pelanggan memasukkan data booking untuk hari X , Jam Y dan Jenis Layanan Z dengan Harga P - maka feedback konfirmasi yang diterima oleh konsumen persis sama.

Tabel 2. Tabel hasil kuesioner UAT

Sumber : Pengujian Internal

\begin{tabular}{|c|c|c|c|c|}
\hline No & Pertanyaan & Setuju & $\begin{array}{l}\text { Ragu- } \\
\text { ragu }\end{array}$ & $\begin{array}{l}\text { Tidak } \\
\text { Setuju }\end{array}$ \\
\hline \multicolumn{5}{|c|}{ Tampilan } \\
\hline 1 & Teks terbaca jelas & 30 & 0 & 0 \\
\hline 2 & Warna teks sesuai dengan latar belakang & 26 & 4 & 0 \\
\hline 3 & Perpaduan warna terlihat menarik & 26 & 4 & 0 \\
\hline 4 & Penempatan button tepat & 30 & 0 & 0 \\
\hline 5 & Keseluruhan tampilan aplikasi terlihat menarik & 30 & 0 & 0 \\
\hline \multicolumn{5}{|c|}{ Fungsi } \\
\hline 1 & Informasi jelas & 27 & 3 & 0 \\
\hline 2 & Fungsi button berjalan dengan baik & 30 & 0 & 0 \\
\hline 3 & Aplikasi memuat informasi jelas dan sesuai & 29 & 1 & 0 \\
\hline \multicolumn{5}{|c|}{ Kemudahan } \\
\hline 1 & Aplikasi dapat di operasikan dengan mudah & 30 & 0 & 0 \\
\hline 2 & Aplikasi nyaman digunakan & 27 & 3 & 0 \\
\hline 3 & $\begin{array}{l}\text { Aplikasi menghemat waktu dalam melakukan komplain terdahap kerusakan } \\
\text { fasilitas dan juga dalam mendapatkan informasi }\end{array}$ & 29 & 1 & 0 \\
\hline & Total & 314 & 16 & 0 \\
\hline
\end{tabular}

Sebagai catatan, tabel requirement definition ini sudah disesuaikan dengan pemetaan proses bisnis Sian Barbershop. Disamping itu - dalam perancangan aplikasi terdapat beberapa fungsi fungsi tambahan yang berguna dalam mempermudah pesanan secara daring. Tabel 3 dibawah ini memperlihatkan hasil pengujian test validitas fungsi untuk memastikan fungsi bekerja dengan baik dan memberikan feedback sesuai dengan formula yang ditulis. 
Tabel 3. Tabel hasil test validitas fungsi

Sumber : Pengujian Internal

\begin{tabular}{lllc}
\hline No & Fungsi Utama & Detil Fungsi & $\begin{array}{c}\text { Sudah Valid/ } \\
\text { tidak }\end{array}$ \\
\hline & User : Manager & & \\
\hline 1 & Pelaporan & Manage laporan piutang & Sudah Valid \\
\hline 2 & & membuat laporan pesanan & Sudah Valid \\
\hline 3 & Pengawasan & Mengawasi persediaan & Sudah Valid \\
\hline 4 & & Mengawasi Data Pesanan & Sudah Valid \\
\hline 5 & $\begin{array}{l}\text { Pengdataan / } \\
\text { Pencatatan }\end{array}$ & Mencatat data pesanan & Sudah Valid \\
& & & \\
\hline & & Mencatat data customer & Sudah Valid \\
\hline & User : Admin & Mencatat laporan pesanan & Sudah Valid \\
\hline 1 & Pelaporan & Menyiapkan laporan pesanan Online & Sudah Valid \\
\hline 2 & & Mengawasi Pesanan Online dari costumer & Sudah Valid \\
\hline 3 & Pengawasan & Mengawasi proses Service & Sudah Valid \\
\hline 4 & & melakukan pendataan terhadap service masing masing & Sudah Valid \\
\hline 5 & Pengdataan / & costumer & \\
\hline & Pencatatan & &
\end{tabular}

\section{KESIMPULAN DAN SARAN}

\section{Kesimpulan}

Kesimpulan yang dapat diambil dari perancangan ini.

1. Rancangan system CRM Sian Barber Apps dapat mendukung usaha barber dalam peningkatan penjualan dengan cara [1] Akuisisi pelanggan baru [2] Mempertahankan pelanggan-pelanggan setia (customer engagement), dan [3] peningkatan cross-selling.

2. Rancangan aplikasi CRM ini berdasarkan pemetaan atas proses bisnis saat ini, identifikasi kebutuhan user (admin dan pelanggan) serta arah pengembangan proses bisnis dan mempertimbangkan kenyamanan pengguna (UI/UX)

3. Sistem CRM ini memberikan data feedback pelanggan, data pelanggan, data penjualan, dan data produk untuk memberi dampak penjualan dan customer engagement pada usaha. Pemetaan proses bisnis yang ada di Sian Barberhop dimulai dari proses booking, proses pemberian layanan, proses penyelsaian transaksi, dan menjaga hubungan dengan pelanggan. Proses ini juga mempunyai manfaat dari data yang diperoleh untuk dipergunakan dalam mengatur keanggotaan.

4. Rancangan sistem Costumer Relationship Management (CRM) Sian Barber Apps memberikan opsi sistem back end untuk admin/manajer dan apps untuk pelanggan yang dapat diakses pelanggan melalui smarphone dan bisa di download dengan mudah di Playstore.

\section{Saran}

Saran-saran untuk pengembangan lebih lanjut adalah :

1. Untuk penelitian dan perancangan selanjutnya dapat dibuat dalam platform iOS dan integrasi dengan berbagai layanan pembayaran dan e-wallet. Ini dapat mengintegrasikan dengan aplikasi yang sudah ada untuk mempersingkat waktu development . 
2. Tampilan antarmuka dibuat sebaik mungkin agar memberikan kemudahan dan pengalaman yang cukup baik bagi pengguna.

3. Kemudian dapat dipertimbangkan untuk menggunakan metode yang lebih agile untuk mengantisipasi dan menyesuaikan dengan perubahan situasi dan requirement.

\section{Ucapan Terima Kasih}

Terimakasih kami sampaikan sebesar-besarnya untuk para pihak, baik di civitas akademika dan stakeholder di lokasi obyek penelitian sehingga tulisan ini dapat diselesaikan dengan baik.

\section{REFERENSI}

Abrial, D. S. (2015). CNN Indonesia: Pria 'Haus' Tampil Gaya, Barbershop Menjamur. Diakses April 2017 dari https://www.cnnindonesia.com/gaya-hidup/20151213124019-27797868/pria-haus-tampil-gaya-barbershop-menjamur/

Anastasia, D., Setiawati L. (2011). Sistem Informasi Akuntansi, Perancangan, Prosedur dan Penerapan. Edisi 1. Andi Yogyakarta, Yogyakarta.

Andreani, F. (2009). "Customer Relationship Management (CRM) dan Aplikasinya dalam Industri Manufaktur dan Jasa”. Surabaya

Anna, L. K. (2017). Penghasilan Menjanjikan dari Bisnis Barbershop. Diakses dari Kompas Lifestyle http://lifestyle.kompas.com/read/2017/07/13/083300320/penghasilan- menjanjikan-daribisnis-barbershop

Aprilyani, J. (2017). Bisnis Barbershop Optimistis tumbuh 30\%.. Diakses dari Kontan Mobile http://m.kontan.co.id/news/bisnis-barbershop- optimistis-tumbuh-30

Griffin, J. (2003). Customer Loyalty Menumbuhkan dan Mempertahankan Kesetiaan Pelanggan. Jakarta: Erlangga.

Kalakota, R., \& Robinson, M. (2001). E-business 2.0: Roadmap for Success. Addison-Wesley Professional, Boston.

Kotler, P. (2005). Manajemen Pemasaran . Jakarta: PT. Indeks Kelompok Gramedia.

Kotler, P., Wong, V., Saunders, J., \& Armstrong, G. (2005). Principles of Marketing. England: Pearson Prentice Hall.

Laudon, K. C., \& Laudon , J. P. (2014). Management Information Systems Managing the Digital Firm. Essex: Pearson.

Payne, A. (2005). HANDBOOK OF CRM: Achieving Excellence in Customer Management.Oxford: Elsevier 
Seminar Nasional Hasil Penelitian dan Pengabdian Kepada Masyarakat 2021

Pengembangan Ekonomi Bangsa Melalui Inovasi Digital Hasil Penelitian dan

Pengabdian Kepada Masyarakat

Jakarta, 21 Oktober 2021

(halaman kosong) 